\title{
Boiling water cooled travelling wave reactor
}

\author{
X.-N. Chen*, F. Gabrielli, A. Rineiski, T. Schulenberg \\ Institute for Nuclear and Energy Technologies, Karlsruhe Institute of Technology, P.O.B. 3640, D-76021 Karlsruhe, Germany
}

Keywords:

Travelling wave reactor

Boiling water reactor

High fuel utilisation

Neutronic and thermal hydraulic coupling

\begin{abstract}
A B S T R A C T
This study investigates the principal possibility of a boiling water cooled travelling wave reactor that can potentially improve the natural uranium utilisation in Boiling Water Reactors (BWRs), and more general in water cooled reactors, appreciably. A strong variation of the water density along the core height makes favourable the nuclear fission in the lower core part and the fuel breeding in the upper one. A serial axial fuel shuffling scheme is considered for establishing a kind of travelling wave. The fresh natural uranium oxide fuel is loaded from the core top. The irradiated fuel is discharged from the core bottom. The water coolant at the saturation point at a near atmospheric pressure comes from the bottom of the core, as in conventional BWRs. The asymptotic state of the breeding/burning wave is obtained, including its major characteristics, such as power density distribution, coolant mass flow rate, and the fuel shuffling speed. The employed simulation model for the water density variation in axial direction is based on a slip ratio approximation for two phase flows. The burn up calculations are performed with the ERANOS2.2 code, in which the models of axial fuel shuffling and coolant density variation have been implemented. The numerical results for 1D models are encouraging and show that the breeding performance is sufficient to keep the core critical in the asymptotic state, and a maximum burn up of about $37 \%$ can be reached, meaning that the natural uranium utilization in BWR can be improved by several ten times compared to conventional water cooled reactors. Feasibility related issues, such as the void reactivity effect and crit ical heat flux limit, has been checked and discussed. Further efforts are needed to establish a viable design based on the ideas proposed in the paper.
\end{abstract}

\section{Introduction}

The mechanism of a self propagating nuclear breeding/burning (B\&B) wave in a fertile medium of ${ }^{238} \mathrm{U}$ or ${ }^{232} \mathrm{Th}$ attracts more and more scientific interest (Feoktistov, 1989; Teller et al., 1996; Seifritz, 2000; van Dam, 2000; Sekimoto et al., 2001; Fomin et al., 2005; Chen et al., 2005; Chen and Maschek, 2005; Chen et al., 2008; Chen et al., 2012; Greenspan, 2012). As already pointed out in (Feoktistov, 1989), the necessary condition for a self propagating $B \& B$ wave is that the fertile fuel could generate asymptotically, i.e. after a long irradiation period, so much fissile material that the chain reaction criticality with such fuel would be possible. This B\&B wave mechanism leads asymptotically to an almost constant reactivity of the system with this wave and a high burn up. This leads, consequently, to a very high utilization of fuel. It is known as "CANDLE" concept (Sekimoto et al., 2001), breed and burn (B\&B) reactor (Greenspan, 2012) and travelling

\footnotetext{
* Corresponding author.

E-mail address: xue-nong.chen@kit.edu (X.-N. Chen).
}

wave reactor (TWR) (Weaver et al., 2009; Hejzlar, 2013). This concept recently received a wider attention due to the engagement of a Bill Gates funded company, TerraPower. This company pro posed a radial fuel shuffling strategy for developing a new variety of TWR based on sodium cooled fast reactor (SFR) technologies (Weaver et al., 2009; Hejzlar, 2013).

However, the sodium cooled TWR faces technical challenges. Besides the sodium coolant technology, we still have difficulties caused by a possible positive coolant void worth and high clad irra diation damage. Therefore it is very attractive to solve this problem with light water reactor technologies, which are much mature industrially than the sodium technology. There were several attempts to apply the TWR concept for a supercritical water reac tor (SCWR) (Schulenberg et al., 2008; Ishiwatari et al., 2001; Mori, 2005; Monti, 2009), which show that the fuel utilization improve ment potential in SCWR is high, but up to now these attempts are not fully successful (Chen et al., 2010; Zhang et al., 2011). The rea son is that there is still too much water in the upper core part, the neutron spectrum is quite soft and the breeding is not sufficient.

Compared to SCWR, the boiling water reactor (BWR) is even a more favourable for the TWR concept due to possibly large 
variations of water density in the water/vapour mixture in the core. If the vapour quality is $10 \%$ and the core pressure is low, e.g. we consider a near atmospheric pressure, the density at the core outlet could be only several percent of that at the core inlet. This implies that the neutron spectrum at the upper part of core could be sufficiently "hard" for breeding. Thus, a combination of fission at the lower part and breeding at the upper part could be considered and the breeding/burning wave, which moves into the breeding part, namely upwards, could be generated in a natural way. Regarding this aspect, the BWR could be a very good applica tion example of the TWR concept. The major concern here is if the breeding is sufficient to make the travelling wave mode be sustain able, i.e. critical in the asymptotic state.

Light water reactors (LWRs) have been commercially operated for more than 50 years. Most of the currently operated nuclear power plants are LWRs, which demonstrates that LWRs are well established technologies. However, LWRs have a rather low natural uranium utilization rate of barely $0.60 .7 \%$ (Greenspan, 2012; Vallet, 2013). This means that from the all uranium used for the nuclear fuel production, only less than $1 \%$ uranium undergoes fis sion reaction and the rest of uranium is either depleted uranium or part of spent fuel. From the scientific point of view, this low ura nium utilization is actually a kind of waste of natural resource, which is not compatible with the aim of long term nuclear energy sustainability. The fuel cycle, including fuel reprocessing is a possi ble solution of the problem, but it is associated with relatively high costs and high technological demands of highly irradiated spent fuel handling. There were scientific and engineering efforts to improve the utilization of fertile materials in LWRs directly, e.g. to increase the conversion ratio by using thorium fuel and hetero geneously arranged breeding zones (Vallet, 2013; Janin et al., 2016), which give limited improvements without recycle of spent fuel. But to our knowledge, an idea to proceed with LWR technolo gies for a dramatic improvement without spent fuel recycling, e.g. to increase the utilization by several tens of times, e.g. 50 times, has not been presented yet.

This paper is an attempt to look for a possibility of TWR in a boiling water reactor. Because of the large variation of the water density axially, the neutron spectrum and the corresponding aver aged one group microscopic cross sections are changed signifi cantly from coolant inlet to its outlet. This requires to consider thermal hydraulic/neutronic coupling, meaning using or develop ing a model for a thermal hydraulic solution of water density vari ation for any given axial power shape. As a first attempt, a $1 \mathrm{D}$ numerical calculation with the ERANOS code (Rimpault, 2002) has been carried out. The solution obtained in this paper is for an asymptotic state of TWR. Obviously the asymptotic material distri bution can be very useful for the ignition transient phase as well. This initial fuel distribution, e.g., of the plutonium enrichment, can be arranged, such that it becomes similar to the asymptotic state, so that the asymptotic state can be reached in a relatively short time. But in this paper we will not investigate ignition transients.

An analytic thermal hydraulic solution of water density as a function of power distribution and a certain coolant flow rate is obtained based on a slip ratio approximation for velocities of water/vapour in the mixture. The water density variation model based on this approximation is implemented in the ERANOS calcu lation. The ERANOS code (Rimpault, 2002) is applied to carry out cross section, neutron transport, and burn up calculations. Here with we consider an axial fuel shuffling scheme for a standing wave in a finitely long core. The main objective of the calculation is to check whether the breeding is sufficient for achieving critical ity, as the neutron flux, the fuel enrichment and the water density are coupled during the fuel drifting.

\section{Numerical calculation scheme and thermal hydraulic model}

\subsection{Axial fuel shuffling strategy and calculation scheme}

The basic idea is that the pin bundle in a fuel assembly (FA) or the fuel assembly itself is divided into several movable blocks. This approach is similar to the case studied in (Zhang et al., 2011) and is illustrated in Fig. 1. The first fresh fuel block is loaded into the core from the top, simultaneously accompanied by unloading the last spent fuel block from the bottom, while the other fuel blocks in between move downwards like a frog leap. The fuel shuffling or fuel jump takes place periodically, e.g. one jump per 600 days. Beginning from an initial condition with fresh fuels loaded in the whole core, an asymptotic state will be approached after certain steps of fuel jump, in which $\mathrm{k}_{\mathrm{eff}}$, the power shape, the nuclide den sities and the coolant density distribution tend to almost stable values. Although we are now considering the axial fuel shuffling case, the solution holds also for the case of power moving over the stationary fuel, i.e. it implies a travelling wave solution in an infinitely long core. As a first attempt, only a $1 \mathrm{D}$ problem is con sidered here.

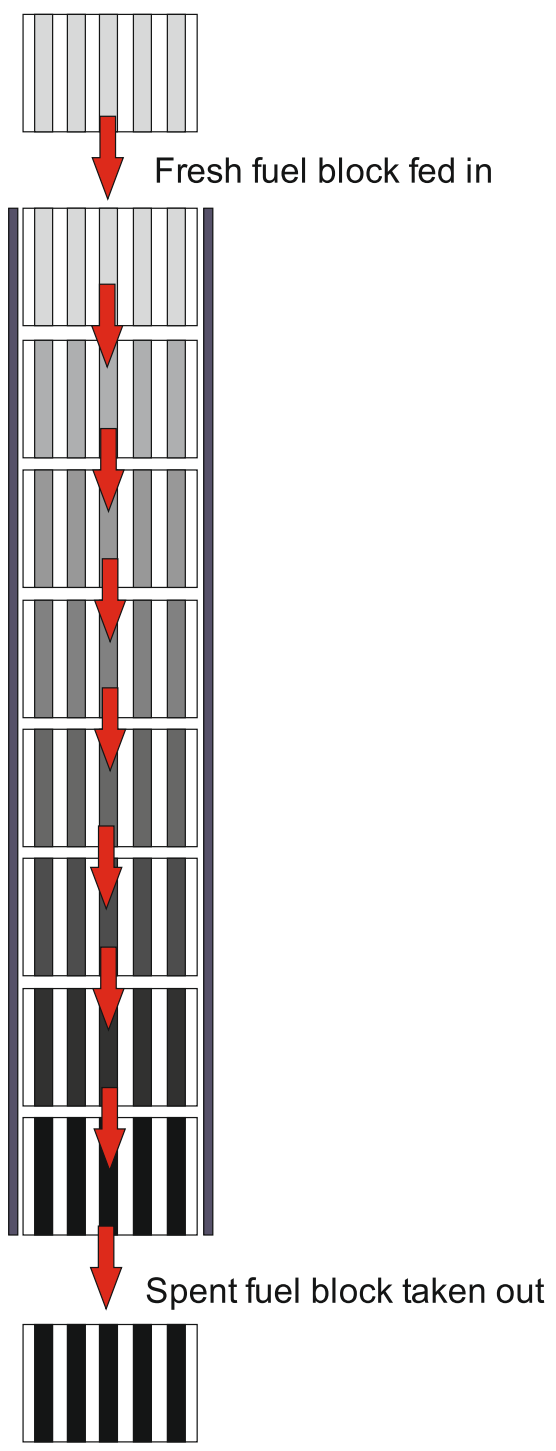

Fig. 1. Schematic diagram of axial fuel shuffling strategy. 
The calculation scheme is built up for the axial fuel shuffling strategy (Zhang et al., 2011), in which the core is firstly divided into several cells along the axial direction and then the initial enrichment, total thermal power and fuel shuffling speed (corre sponding to burn up time steps) are adjusted for achieving the asymptotic state at the desired $\mathrm{k}_{\text {eff }}$ level. In this paper, the ECCO code with JEFF3.1 (The JEFF 3.1 Nuclear Data Library, 2006) data library is used to generate microscopic cross sections of the nuclides, and the ERANOS code is adopted to perform the neutron ics and the burn up calculations with 40 energy groups and 80 fis sion products by applying the nodal diffusion model of VARIANT.

The coupling between neutronics and thermal hydraulics is an important issue in this simulation, which is illustrated in Fig. 2. Explicitly speaking, the power distribution provided by neutronics will be coupled to the effective water density of the water vapour mixture provided by the thermal hydraulics under certain cooling condition (for a certain coolant flow rate). This can be realized by an iteration procedure of the forward time scheme. In each time (iteration) step, the neutronic part provides the power distribution to the thermal hydraulic part and then the thermal hydraulic part calculates the coolant density for the next step of neutronic calcu lation. So the iteration continues until a convergent state is reached, which is considered to be an asymptotic state. The ther mal hydraulic model will be described in detail in the next subsection.

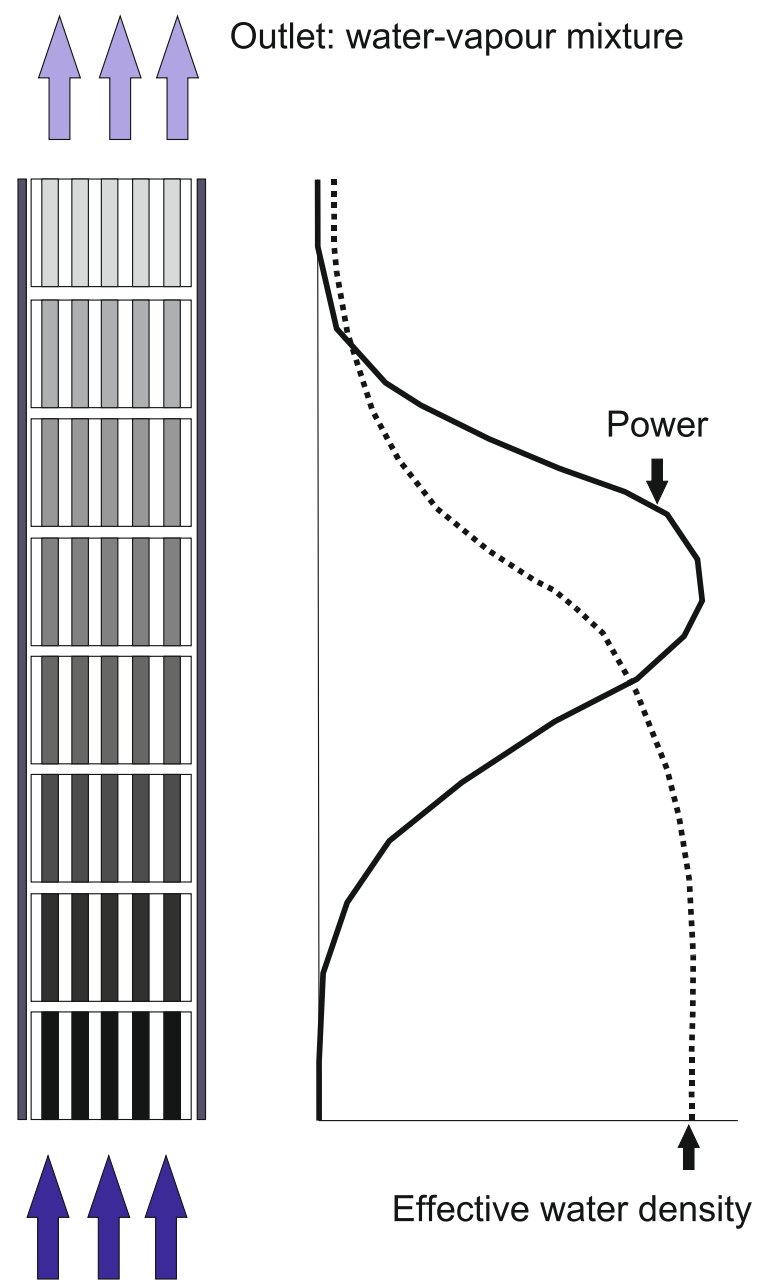

Inlet: water

Fig. 2. Schematic diagram of coupling between neutronics (power) and thermal hydraulics (water density) in an asymptotic state.

\subsection{Single channel thermal hydraulic model of water boiling}

For neutronic calculations we need a spatial distribution of water density. The coupling between neutronics and thermal hydraulics is implemented in such a way that the neutronic part provides the power to the thermal hydraulic one, while the ther mal hydraulic part provides the effective water density to the neu tronic one. The temperature feedback effects are of second order importance in this problem and will not be taken into account here.

For the sake of simplicity we assume that the water at the core inlet is $100 \%$ liquid at the saturation temperature under a certain pressure. The coolant in the core is a water vapour mixture with a certain velocity slip ratio, which is determined by a correlation discussed later. Since we consider a very long time scale of several years, the coolant flow can be regarded and treated as one at steady state.

Now we consider a single subassembly channel flow with the mass flow rate $\dot{m}$ and the flow area $A$. According to the mass con servation, the sum of the mass flow rates of water and vapour should be constant over the whole channel as

$\dot{m}_{w}+\dot{m}_{v} \quad \dot{m}_{w, 0} \quad \dot{m} \quad$ const

where $\dot{m}_{w}$ and $\dot{m}_{v}$ are the water and vapour mass flow rates, and $\dot{m}_{w, 0}$ the core inlet water mass flow rate, being equal to the total water mass flow rate $\dot{m}$.

The next step is to consider the energy conservation. Since the water vapour mixture is already and always at the saturation con dition, e.g. $T=100^{\circ} \mathrm{C}$ at $1 \mathrm{bar}$, the nuclear thermal energy is con verted totally to the water boiling. Thus, for the single channel with linear power $\chi$, we have

$\Delta \dot{m}_{v} h \quad \chi \Delta z$

where $h$ is the water boiling latent heat. This means the decrease of the water mass flow rate that is the boiling water mass rate is equal to the thermal power. In this case the vapour mass quality $x$ can be simply determined as

$x \frac{\dot{m}_{v}}{\dot{m}_{w, 0}} \quad \int_{0}^{z} \frac{\chi}{\dot{m}_{w, 0} h} d z$

Herewith we introduce an important parameter defined as

$k \frac{\chi}{\dot{m}_{w, 0} h}$

which characterizes the water boiling process, has a dimension of reciprocal length and, therefore, is called as boiling length number. Obviously $k$ is variable over the core length, i.e. a function of $z$.

In order to get the effective water density we have to get the relative volume fraction of vapour, the so called void fraction denoted as

$\varepsilon \frac{\alpha_{v}}{\alpha_{w}+\alpha_{v}}$

which $\alpha_{v}$ and $\alpha_{w}$ are vapour and water volume fractions. The void fraction $\varepsilon$ is one of the most important parameters used to charac terize two phase flows, see (THOME 2004) for more information. The simplest analytic solution is the homogeneous water vapour mixture model, where it is assumed that water and vapour have the same velocity. In terms of the total mass flow rate $\dot{m}$, the vapour quality $x$ and the void fraction $\varepsilon$, the vapour and water velocities can be expressed as

$u_{v} \frac{\dot{m}}{\rho_{v}}\left(\frac{x}{\varepsilon}\right), u_{w} \quad \frac{\dot{m}}{\rho_{w}}\left(\frac{1}{1} \frac{x}{\varepsilon}\right)$

where subscripts $w$ and $v$ stand for water and vapour, respectively, and $\rho$ the theoretical density. Thus, from the above expressions 
while assuming equal velocities for two phases, we obtain the homogeneous void fraction, denoted as $\varepsilon_{h}$,

$$
\varepsilon_{h} \frac{1}{1+\left(\frac{1 x}{x}\right) \frac{\rho_{v}}{\rho_{w}}}
$$

In general, the homogeneous void fraction model is reasonably accurate for only a limited range of circumstances. In the special case, where the density ratio is very small, $\varepsilon_{h}$ is significantly over estimated, which leads to a too small effective density in the upper part of the core.

A natural correction of this model is to assume that the two phases have two different mean velocities, $u_{v}$ and $u_{w}$, and to intro duce their ratio into the homogeneous model. The velocity ratio is usually referred as the so called slip ratio $S$

$S \frac{u_{v}}{u_{w}}$

Substituting the velocity expressions (6) into (8) we obtain immediately

$$
\varepsilon \frac{1}{1+\left(\frac{1 x}{x}\right) \frac{\rho_{v}}{\rho_{w}} S}
$$

Of course, if $S=1$, (9) will return to the homogeneous result (7).

There are many analytic solutions and empirical correlations for the slip ratio $S$. For our purpose we adopt the Zivi's first model (THOME 2004; Zivi, 1964).

$S\left(\frac{\rho_{w}}{\rho_{v}}\right)^{\frac{1}{3}}$

Finally the void fraction is expressed as

$$
\varepsilon \frac{1}{1+\left(\frac{1 x}{x}\right)\left(\frac{\rho_{v}}{\rho_{w}}\right)^{\frac{2}{3}}}
$$

where the vapour quality $x$ has been obtained from the energy bal ance (3). It is only remarked without detailed discussions that this expression leads to a reasonable void fraction value in the mass flux range around $400 \mathrm{~kg} /\left(\mathrm{m}^{2} \mathrm{~s}\right)$, while the homogeneous model pro vides an upper limit of the void fraction, see Fig. 17.8 in (THOME 2004).

The vapour to water density ratio can be regarded as a constant in the core, as the pressure change is negligible. It can be seen e.g. that $\rho_{v} / \rho_{w} \approx 1 / 1600$ at atmospheric pressure and $\rho_{v} / \rho_{w} \approx 1 / 172$ and $1 / 59$ at the pressure of 10 and 28 bar, respectively. The relative effective water density in terms of $\varepsilon$ is finally expressed as

$\frac{\rho}{\rho_{0}} \quad\left(\begin{array}{ll}1 & \varepsilon\end{array}\right)+\frac{\rho_{v}}{\rho_{w}} \varepsilon$

This water density variation is exactly what we need for the neu tronic calculation. Sometime we use the relative water volume frac tion $\beta$, which is defined as

$$
\beta \frac{\alpha_{w}}{\alpha_{w}+\alpha_{v}} \quad 1 \quad \varepsilon
$$

As an example, for $10 \%$ vapour quality under atmospheric pres sure, the relative water vapour mixture densities at the outlet with respect to the inlet one are 0.0062 and 0.062 according to the homogeneous and Zivi's slip ratio models, respectively. It has to be remarked here that the homogeneous model clearly overesti mates the void fraction and results in a significantly underesti mated effective water vapour mixture density, while the slip ratio model is more realistic and results in maximal values of effec tive water vapour mixture density among several correlation mod els for a mass flux range of a realistic BWR around $1000 \mathrm{~kg} /\left(\mathrm{m}^{2} \mathrm{~s}\right)$, see (THOME 2004, page 17.20). This means that the thermal hydraulic model applied here is conservative regarding the aspect of breeding. In other words, if this model predicts that the breeding is sufficient, it should be more than sufficient in the reality.

\subsection{Discussions on major parameters and boiling crisis}

The linear power is defined as power per length as $\chi(z) \quad d P / d z$ for a certain pin or a certain sub assembly channel or even for the whole reactor core. The axial power distribution is usually normal ized by its average as

$\chi(z) \quad \frac{\chi(z)}{\chi_{0}}$

where is $\chi_{0}$ the average value of the linear power. The maximum value of $\chi(z)$ corresponds to the power peaking factor in the $1 \mathrm{D}$ case. In the special case here, the boiling length number $k$ can be normalized as

$k(z) \quad k_{0} \frac{\chi(z)}{\chi_{0}}$ with $k_{0} \quad \frac{\chi_{0}}{\dot{m}_{w, 0} h}$

Since the length unit used in the neutronic code is $\mathrm{cm}, \chi$ is in $W / \mathrm{cm}$ and $k$ in $\mathrm{cm}^{1}$.

Integration of $k(z)$ over the whole core results in the ratio of the total power to the total water boiling latent power, i.e. $P / \dot{m}_{w, 0} h$, which is exactly the vapour mass quality at the core outlet. Thus, the vapour mass quality at the core outlet can be expressed in terms of $k_{0}$ as

$x_{\text {outlet }} \frac{P}{\dot{m}_{w, 0} h} \quad k_{0} L_{\text {core }}$

where $L_{\text {core }}$ is the core length. The vapour mass quality in a BWR is usually in the range between $10 \%$ and $20 \%$. We may choose these two typical values for our calculation examples. This means the reactor power is $10 \%$ or $20 \%$ of the total water boiling latent power.

\subsection{Critical heat flux}

There is another important issue to be discussed here. That is the boiling crisis. Usually the boiling crisis or the critical heat flux (CHF) can be characterised by a critical value of the ratio of the heat flux $q_{\mathrm{x}}$ to the mass flux $G$, i.e.

$\frac{q_{x}}{G}<$ critical value in $\mathrm{kJ} / \mathrm{kg}$

As we consider the fuel subassembly flow, the average heat flux and the mass flux can be expressed as

$q_{x} \frac{\chi_{\text {pin }}}{\pi d_{\text {pin }}} \quad \frac{\chi_{F A}}{\pi d_{\text {pin }} N_{\text {pin }}}, G \quad \frac{\dot{m}}{A_{\text {coolant }}}$

where $d_{\text {pin }}$ is the pin diameter, $N_{\text {pin }}$ the number of pins in a fuel assembly and $A_{\text {coolant }}$ the coolant flow cross sectional area. There fore we have the relationship between $k_{0}$ and $q_{x} / G$ as

$$
\frac{q_{x}}{G} \quad \frac{\chi_{F A} h A_{\text {coolant }}}{\dot{m} h \pi d_{\text {pin }} N_{\text {pin }}} \quad k_{0} \frac{h A_{\text {coolant }}}{\pi d_{\text {pin }} N_{\text {pin }}} \quad \frac{k_{0} D_{x}}{4} h \text { with } D_{x} \quad \frac{4 A_{\text {coolant }}}{\pi d_{\text {pin }} N_{\text {pin }}}
$$

where $D_{\mathrm{x}}$ can be called as the equivalent heat flux tube diameter. This is of course the average heat flux to the mass flux ratio. The maximum ratio has to be multiplied by the total power peaking fac tor $f_{\text {peak. }}$

$\frac{q_{x, \max }}{G} \quad \frac{f_{\text {peak }}}{4} k_{0} D_{x} h$

For certain pressure, mass flux and vapour quality, the critical heat flux can be looked up from the table in (Groeneveld, 2007). 
For example, for the pressure of 1 bar and the vapour quality $x=0.2$, it can be derived that

$\frac{q_{x, C H F}}{G} \quad 1.50$ and $2.00 \mathrm{~kJ} / \mathrm{kg}$ for $G \quad 2000$ and $1000 \mathrm{~kg} /\left(\mathrm{m}^{2} \mathrm{~s}\right)$

For a smaller vapour quality $x$, this value is even higher. For instance, for $x=0.1$,

$\frac{q_{x, \mathrm{CHF}}}{G} \quad 1.70$ and $2.35 \mathrm{~kJ} / \mathrm{kg}$ for $G \quad 2000$ and $1000 \mathrm{~kg} /\left(\mathrm{m}^{2} \mathrm{~s}\right)$

\subsection{Configuration of fuel assembly and pins and coolant density variation}

As a continuation to the numerical SCWFR study (Zhang et al., 2011), the SCWFR seed SA/pin design (Ishiwatari et al., 2001) are chosen and modified. Only a one dimensional case is considered in current numerical simulations and the core is assumed to be filled with fuel subassemblies. The number of fuel pins is changed to 169 , as the usual 6 control pins are replaced by fuel pins. The fuel pin diameter is modified to be $1.083 \mathrm{~cm}$ and its pitch $1.158 \mathrm{~cm}$ from their original values of $1.02 \mathrm{~cm}$ and $1.15 \mathrm{~cm}$. There fore the fuel, steel, and coolant volume fractions that are used in the neutronic calculations are $54.9 \%, 20.7 \%$ and $24.4 \%$, respectively. Their theoretical densities of $10.45,6.23$ and $0.958 \mathrm{~g} / \mathrm{cm}^{2}$ are taken in the calculation. The necessary geometric data are given in Table 1 . The core length is $165 \mathrm{~cm}$ and the average fuel power den sity is $200 \mathrm{~W} / \mathrm{cm}^{3}$. This is a very tight arrangement of fuel pins. What we did is just to choose the boiling length number $k_{0}$ to ensure the criticality condition and the CHF condition to be satis fied. Further check of the thermal hydraulic conditions and improvement of the design should be done.

The core is assumed to be at the near atmospheric pressure of 1.013 bar, because we need a very strong water density reduction at the core outlet for sufficient breeding there. Table 2 shows den sity differences in typical cases, e.g. at atmospheric pressure (the first line) and at a typical BWR pressure (the last line). The relative water vapour mixture density, i.e. the ratio of the mixture density to the water one, can be also calculated for certain vapour quality and various pressures. For example, for $10 \%$ and $20 \%$ vapour qualities the relative water vapour mixture densities are given in Table 3 , which vary from 0.06 to 0.58 with the pressure from

Table 1

Fuel assembly and pin geometric data.

\begin{tabular}{ll}
\hline Variable & Value, Unit \\
\hline Pitch of FA & $160 \mathrm{~mm}$ \\
Gap between FAs & $2 \mathrm{~mm}$ \\
Thickness of FA wrapper & $2 \mathrm{~mm}$ \\
Number of fuel pins per FA & 169 \\
Fuel pin diameter & $10.83 \mathrm{~mm}$ \\
Fuel pin pitch & $11.58 \mathrm{~mm}$ \\
Clad thickness & $0.56 \mathrm{~mm}$ \\
Active fuel height & $1650 \mathrm{~mm}$ \\
\hline
\end{tabular}

Table 3

Effective and relative water densities for vapour qualities $\mathrm{x}=10 \%$ and $20 \%$ at several typical saturation pressures.

\begin{tabular}{llll}
\hline $\begin{array}{l}\text { Pressure In } \\
\text { bar }\end{array}$ & $\begin{array}{l}\text { Temperature } \\
\text { in }{ }^{\circ} \mathrm{C}\end{array}$ & $\begin{array}{l}\text { Relative water } \\
\text { density } \mathrm{x}=10 \%\end{array}$ & $\begin{array}{l}\text { Relative water } \\
\text { density } \mathrm{x}=20 \%\end{array}$ \\
\hline 1.013 & 100 & 0.06222 & 0.02897 \\
10.02 & 180 & 0.22983 & 0.11962 \\
19.06 & 210 & 0.31872 & 0.17643 \\
74.37 & 290 & 0.58424 & 0.39610 \\
\hline
\end{tabular}

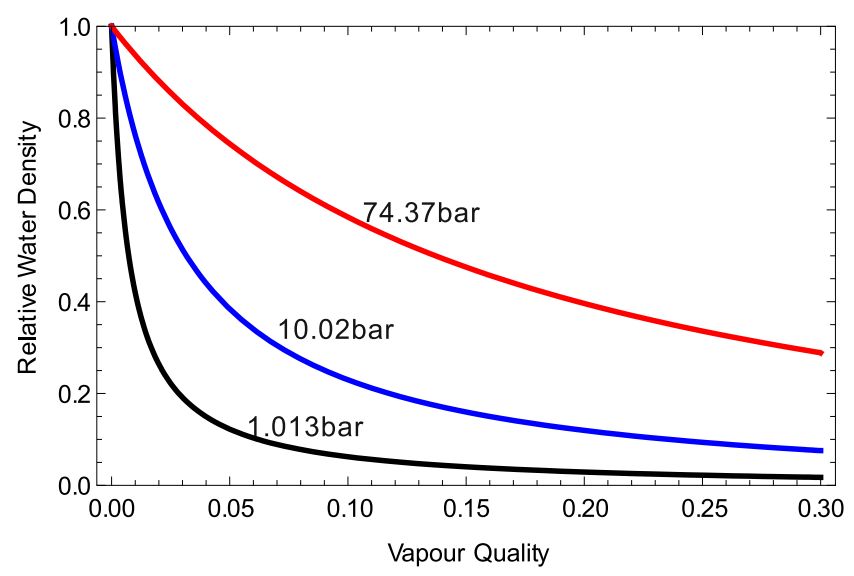

Fig. 3. The relative water density of water-vapour mixture as function of vapour quality and pressure.

atmospheric one to 74 bars for the $10 \%$ vapour quality and 0.029 to 0.40 for the $20 \%$ one. The pressure decrease results in a signifi cant reduction of effective water density at the core outlet. This is why we choose near atmospheric pressure in this study. A gen eral overview of the relative water density as function of vapour quality and pressure is given in Fig. 3 .

\section{Numerical results and discussions}

The $1 \mathrm{D}$ numerical model is a single pin surrounded by coolant with reflection boundary conditions in plane. The average fuel power density per fuel volume is assumed to be $200 \mathrm{~W} / \mathrm{cm}^{3}$, which is roughly $100 \mathrm{~W} / \mathrm{cm}^{3}$ per total volume of fuel, structure and cool ant. The core length is assumed to be $165 \mathrm{~cm}$. This means the total pin power is $26.965 \mathrm{~kW}$, the average linear pin power is 163.43 $\mathrm{W} / \mathrm{cm}$ and the corresponding average heat flux is $48.0 \mathrm{~W} / \mathrm{cm}^{2}$. The core length is divided into 33 nodes, i.e. $5 \mathrm{~cm}$ per node. Physically, the pin bundle in a subassembly (SA) is divided into 33 movable blocks, which is similar to the case studied in (Zhang et al., 2011) and is illustrated in Fig. 1. In the asymptotic operation mode the first fresh fuel pin bundle block is loaded into the core from the top, while the last spent fuel bundle block is discharged from the bottom. By each fuel shuffling every fuel block moves downwards at a jump step. Therefore the fuel shuffling speed can be expressed as $5 \mathrm{~cm}$ per 600 days for example. The fresh fuel is the natural uranium oxide. A typical BWR steel is assumed here.

Table 2

Water and vapour densities and their ratio at several typical saturation pressures.

\begin{tabular}{lllll}
\hline Pressure in bar & Temperature in ${ }^{\circ} \mathrm{C}$ & Boiling latent heat in $\mathrm{kJ} / \mathrm{kg}$ & Water density in $\mathrm{kg} / \mathrm{m}^{3}$ & Vapour density in $\mathrm{kg} / \mathrm{m}^{3}$ \\
\hline 1.013 & 100 & 2257 & 958.4 & 0.5975 \\
10.02 & 180 & 2015 & 887.1 & 5.154 \\
19.06 & 210 & 1900 & 852.8 & 9.580 \\
74.37 & 290 & 1477 & 732.2 & 39.12 \\
\hline
\end{tabular}


Besides the power, the mass flow rate and the fuel shuffling speed are two other important parameters, which are to be deter mined. Table 4 shows general parameters that are used for all the calculation cases. The boiling length number $\mathrm{k}_{0}$ represents the ratio of power to mass flow rate. The higher the value of $\mathrm{k}_{0}$, the higher the vapour quality and the lower the effective water density at the core outlet. We tried various values of $\mathrm{k}_{0}$ and several fuel shuf fling speeds and found that the cases of $\mathrm{k}_{0}=0.0013 \mathrm{~cm}{ }^{1}$ with fuel shuffling speeds around $5 \mathrm{~cm}$ per 600 days are interesting. First of all, since $\mathrm{q}_{\mathrm{x}} / \mathrm{G}$ is given in Table 4 , the mass flux $\mathrm{G}$ is calculated as $1739 \mathrm{~kg} /\left(\mathrm{m}^{2} \mathrm{~s}\right)$ for the chosen parameters. The vapour quality at the outlet is 0.215 and that at the highest power is about 0.12 . The peak value of $q_{x} / G$, which is its average value times the peak ing factor, is about 1.2 for all fuel shuffling speeds. Therefore it is clearly below the limit of CHF given in (21a, b). Table 5 summarizes major results of parametric studies with three fuel shuffling speeds of $5 \mathrm{~cm} / 500 \mathrm{~d}, 5 \mathrm{~cm} / 600 \mathrm{~d}$ and $5 \mathrm{~cm} / 650 \mathrm{~d}$. The fuel shuffling speeds of $5 \mathrm{~cm} / 500 \mathrm{~d}$ and $5 \mathrm{~cm} / 600 \mathrm{~d}$ can make the reactor to reach a crit ical asymptotic state. The other one $(5 \mathrm{~cm} / 650 \mathrm{~d})$ has a slightly sub critical asymptotic state. Their power peaking factors are 4.1 for Case 2 and about 4.4 for the other two cases and their discharged fuel burn ups vary from $32.9 \%$ to $42.5 \%$.

Fig. 4(a c) show distributions of power, water density and $\mathrm{Pu}$ enrichment at the asymptotic state for the three fuel shuffling speeds. For the slowest fuel shuffling of $5 \mathrm{~cm} / 650 \mathrm{~d}$ in case (c) of Fig. 4, the power profile still remains at the upper part of the reac tor; for the fastest fuel shuffling of $5 \mathrm{~cm} / 500 \mathrm{~d}$ in case (a) of Fig. 4 , the power profile moves already to the lower part of the reactor; and for the middle fuel shuffling of $5 \mathrm{~cm} / 600 \mathrm{~d}$ in case (b) of Fig. 4, the power peak stays almost at the centre of the reactor. Since the numerical iterations had to be truncated after certain steps, the numerical results are only near the asymptotic states. Theoretically there is only one particular fuel shuffling speed, which is an eigenvalue of the system and makes the wave stable in the core (Chen et al., 2012). The result of case (b) means $5 \mathrm{~cm} / 600 \mathrm{~d}$ is close to this eigenvalue. For all the three cases the effective power profile length is about $1 \mathrm{~m}$, considerably smaller than the total core length. The effective power peaking factor based on the effective core length is therefore reduced at least to $2 / 3$ of the value listed in Table 5, i.e. about 2.7 and 2.9, respectively. The power profile length is indeed the wave length of this kind of travelling wave reactor, which is an inherent property of the $\mathrm{Pu} \mathrm{U}$ conversion process (Chen et al., 2012). The short effective reactor length is favourable for achieving a compact reactor design. From the feasibility point of view, the fuel shuffling speed of $5 \mathrm{~cm} / 600 \mathrm{~d}$ is the best one in these three cases, which has highest $\mathrm{k}_{\text {eff }}$ and the central power position. The high burn up means not only high fuel utilization, but also a low amount of spent fuel per generated unit energy (a measure of nuclear waste). Fig. 5(a c) show further distributions of major isotopes or lumped isotopes at the asymptotic state for the three fuel shuffling speeds.

The core void worth is a very important issue to be discussed. It is calculated that the core void worth is $766 \mathrm{pcm}$ by $10 \%$ coolant

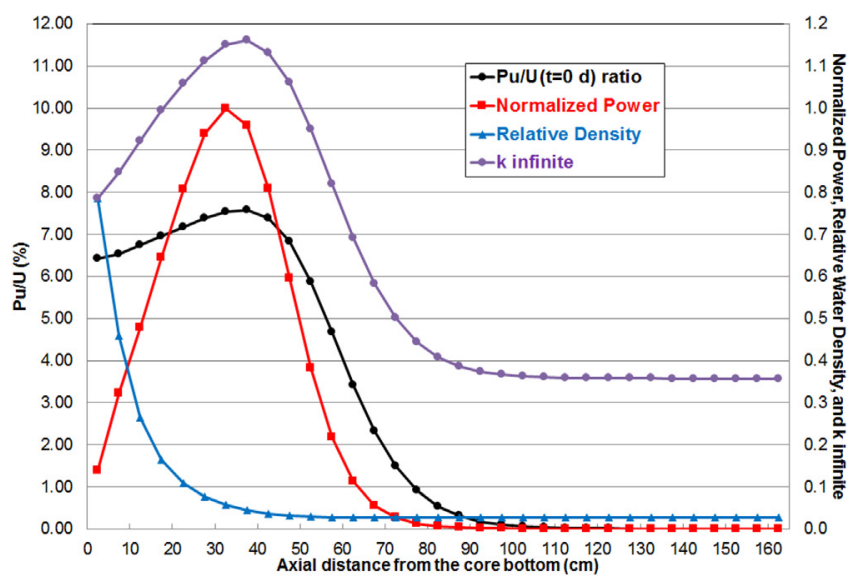

(a)

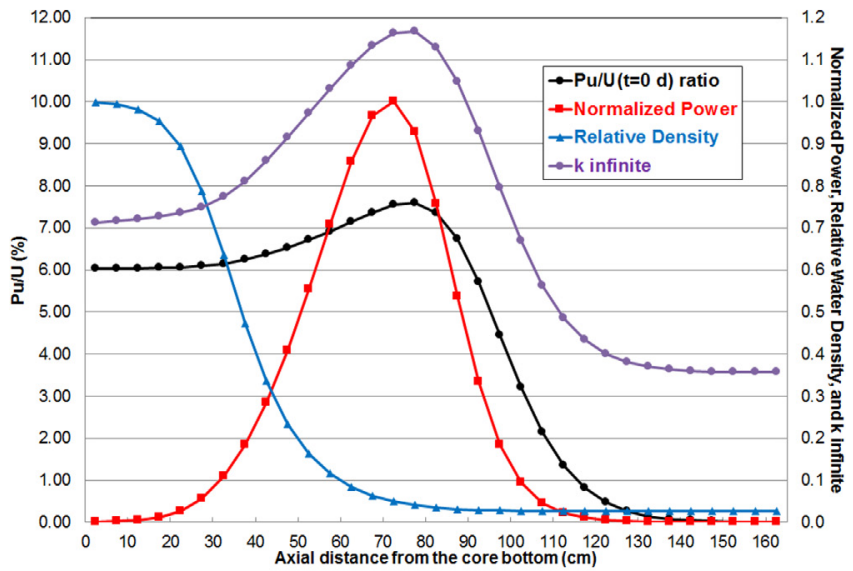

(b)

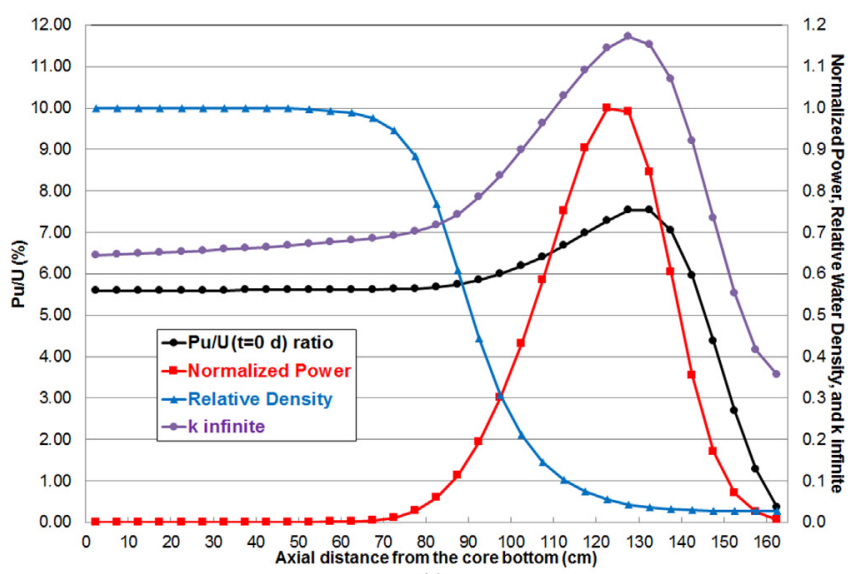

(c)

Fig. 4. Calculated results of power, water density, Pu enrichment and k-infinite in the asymptotic states: (a) $5 \mathrm{~cm}$ per $500 \mathrm{~d}$, (b) $5 \mathrm{~cm}$ per $600 \mathrm{~d}$, and (c) $5 \mathrm{~cm}$ per $650 \mathrm{~d}$.

Table 4

General parameters, which are used for all the calculated cases.

\begin{tabular}{llll}
\hline $\begin{array}{l}\text { General Parameters } \\
\mathrm{L}_{\text {core }}[\mathrm{cm}]\end{array}$ & $\mathrm{k}_{0}\left[\mathrm{~cm}^{1}\right]$ & Vapour quality $\mathrm{x}$ at outlet & Relative water density $\rho / \rho_{0}$ at outlet \\
\hline 165 & 0.0013 & 0.2145 & 0.02668 \\
\hline
\end{tabular}

Table 5

Overview of calculation results.

\begin{tabular}{|c|c|c|c|c|c|c|c|c|}
\hline \multicolumn{3}{|c|}{ Case $1: 5 \mathrm{~cm} / 500 \mathrm{~d}$} & \multicolumn{3}{|c|}{ Case $2: 5 \mathrm{~cm} / 600 \mathrm{~d}$} & \multicolumn{3}{|c|}{ Case $3: 5 \mathrm{~cm} / 650 \mathrm{~d}$} \\
\hline & Power peaking factor & Burn-up & $\mathrm{k}_{\mathrm{eff}}$ & Power peaking factor & Burn-up & $\mathrm{k}_{\mathrm{eff}}$ & Power peaking factor & Burn-up \\
\hline 1.00518 & 4.39 & $32.9 \%$ & 1.01977 & 4.10 & $37.6 \%$ & 0.99810 & 4.43 & $42.5 \%$ \\
\hline
\end{tabular}


void and $4576 \mathrm{pcm}$ by $50 \%$ coolant void for Case 2 with $5 \mathrm{~cm} / 600 \mathrm{~d}$. They are significantly positive and similar for all fuel shuffling speeds. With such a large positive void worth (coolant feedback), this core is not safe for operation. In general this is a key problem for Pu U based fast reactors, which must be solved. Usually it can be solved by increasing neutron leakage brought about by a core geometrical change. But, since the breeding ability is limited in the current concept, we might not be able to use this method.

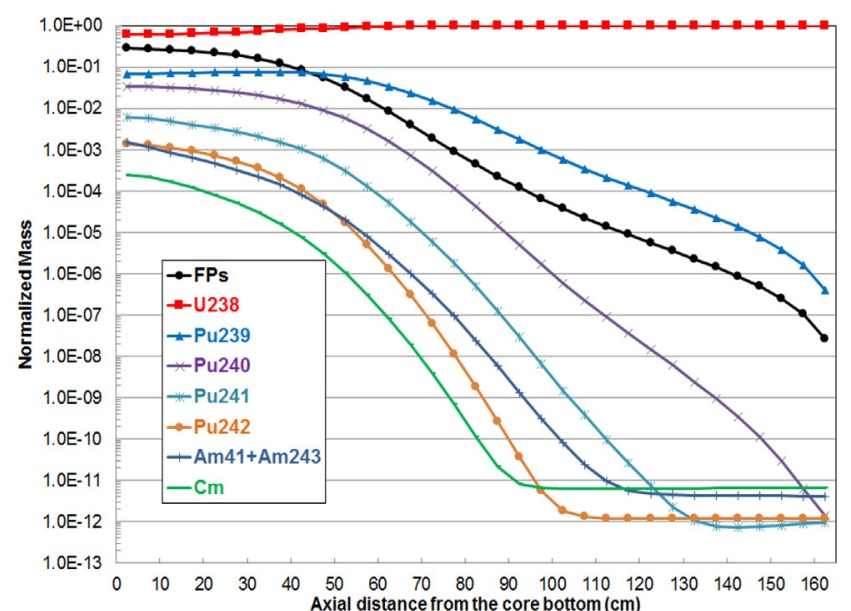

(a)

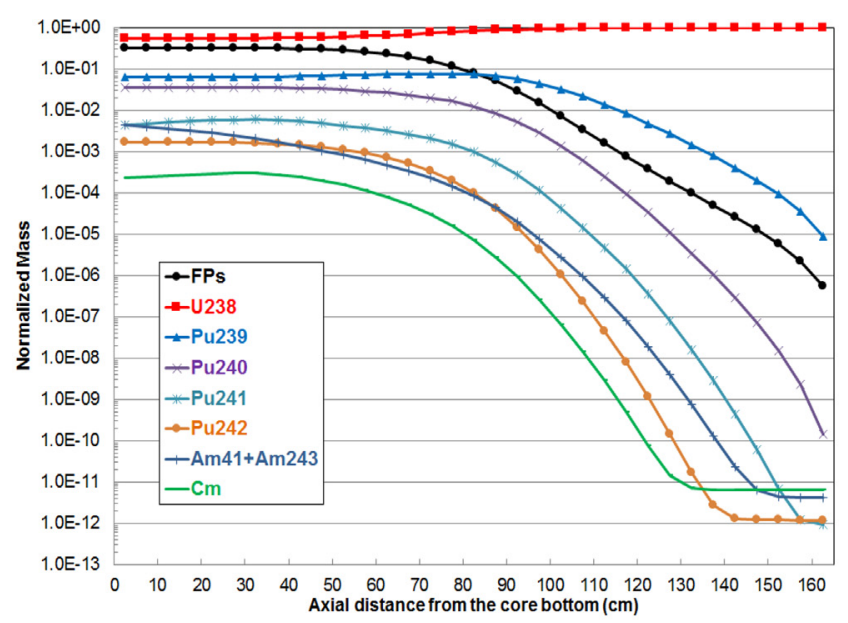

(b)

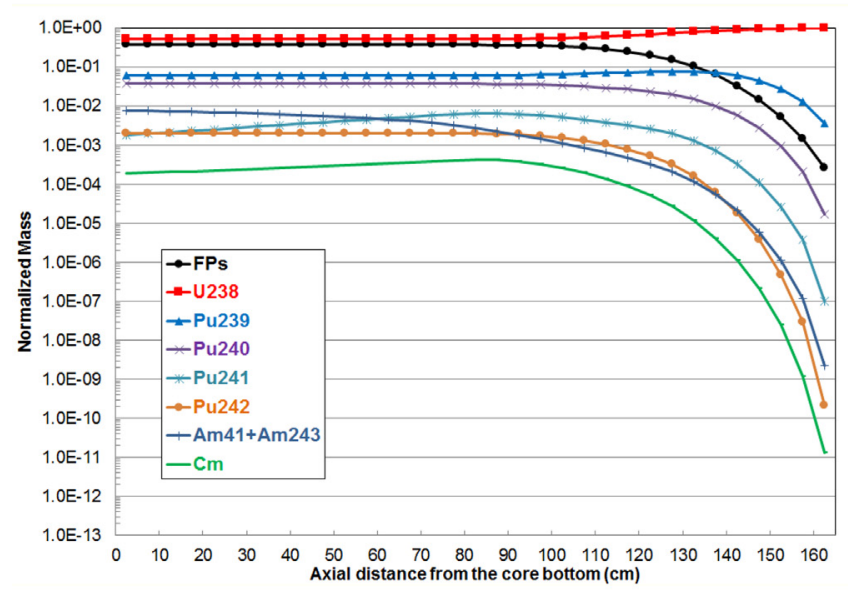

(c)

Fig. 5. Calculated results of major isotope distributions in the asymptotic states: (a) $5 \mathrm{~cm}$ per $500 \mathrm{~d}$, (b) $5 \mathrm{~cm}$ per $600 \mathrm{~d}$, and (c) $5 \mathrm{~cm}$ per $650 \mathrm{~d}$.
However it can be improved, if we use thorium fuel or thorium/ uranium mixed fuel as fresh fuel, as we've already shown in our study of supercritical water reactor (Zhang et al., 2011), where the void worth is reduced from a positive value to negative one, by replacing the uranium oxide with thorium oxide. Besides this most important aspect of thorium fuel, it has two other advan tages: (1) higher breeding ratio and (2) higher Doppler constant in thermal and epi thermal spectra. The excess breeding ratio can be used for increasing the reactor operation pressure. Increas ing the pressure is also an important issue for direct using the water vapour mixture for electricity generation.

Fig. 6 shows neutron spectrum distributions at core top and bottom and the power peak position in the case of $5 \mathrm{~cm} / 600 \mathrm{~d}$. In general they are epi thermal, since the thermal spectrum peak is not visible and they are softer than a real fast reactor spectrum. Due to the dominating influence of fission born high energy neu trons, the "hardest" neutron spectrum can be found near the posi tion of maximum power density. Moreover the water content there is reduced to less than $5 \%$ of the inlet one, and its spectrum is sig nificantly harder than that at the bottom (water inlet). As seen as well in Fig. 6, the spectrum at the core top becomes softer again than the maximum power one. For the interpretation of the energy dependence of the neutron spectra shown in Fig. 6 one has to take into account not only the axial distribution of the water density, but in addition the axial distributions of fissile material and fission products, which differ for the TWR significantly from those encountered in conventional LWRs. Just to mention the most obvi ous aspect: fissile material and fission products, as strong thermal absorbers, are practically absent in the top region, but a large amount of them exists in the bottom region.

Such a high burn up is a challenge for the fuel, even for thermal reactors, which is a general problem for TWR. However, as it has already been recognised in (Zhang et al., 2011), the radiation dam age (dpa) of the cladding in such an LWR is much milder than that in a fast reactor for the same burn up. This is because its spectra are softer and, consequently, for the same burn up the average radiation damage cross section and the neutron fluence experi enced by the fuel and clad are reduced. The results shows that the half of whole burn up (fission) takes places in a region with more than $10 \%$ relative water density, where the spectrum is rela tively soft. The finally irradiated fuel is discharged from the bot tom, where the water is fully filled. This means that the higher burned fuel pins are staying in the more water filled lower region, where the spectra are softer.

Finally we would like to give a comment on the solution described. Although we obtain the solution with the axial fuel shuffling scheme, we actually do not need this fuel shuffling. Instead of it we can use a long core, so that the breeding fission, or saying breeding burning, wave has enough space to drift on the fixed fuel. It is indeed possible, since the effective wave length is only less than one meter and the core length can be three meters. The wave drift speed is about $3 \mathrm{~cm}$ per year. This means it can run 100 years with a four meter core, without fuel shuffling or loading. By the way it can be also envisaged that the excess reactivity and wave drift speed can be controlled by using vertical control rods, which can be withdrawn slowly corresponding to a wave drift speed.

\section{Conclusion}

This paper studies the possibility of a boiling water cooled trav elling wave reactor. The analytic thermal hydraulic solution for water density is obtained and used for neutronic calculations. In the low pressure case, it has been shown that the breeding is suf ficient and, thus, an asymptotic travelling wave state exists in a 


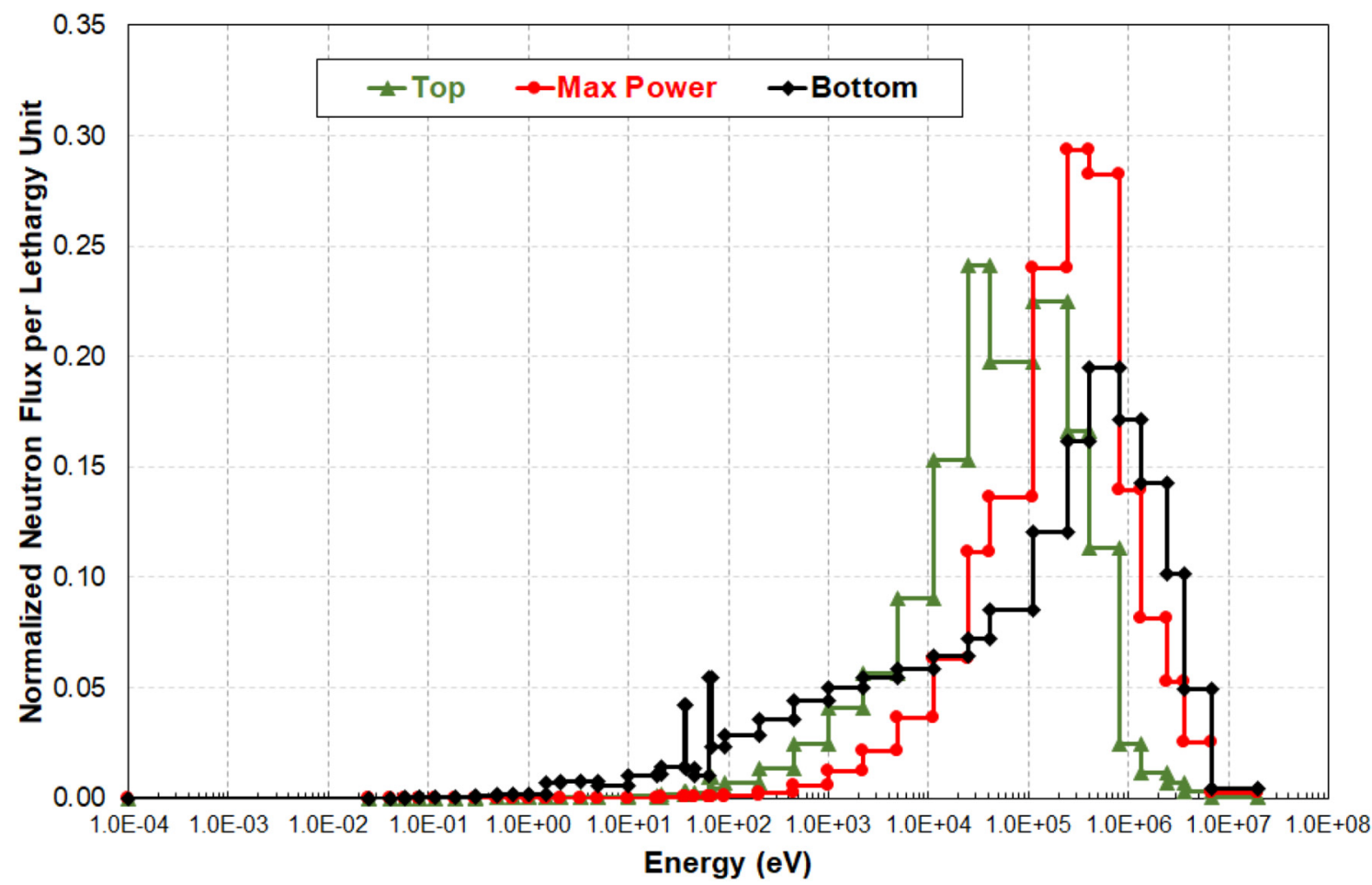

Fig. 6. Calculated results of spectrum distributions in the asymptotic state of $5 \mathrm{~cm}$ per $600 \mathrm{~d}$, where "Top" and "Bottom" stand for cells at the core top and bottom and "Max Power" for the cell with maximal power.

low pressure BWR. This means that the high burn up, high fuel uti lization and low nuclear waste can be achieved with existing BWR technology. This is a seeding idea that can make nuclear energy much more sustainable.

\section{Acknowledgment}

The authors would like to thank Dr. E. Kiefhaber, retired scientific member of KIT (former Karlsruhe Research Centre, FZK), for his valuable discussions in the early time and a thorough scrutiny of this paper.

The first author X N C wishes to express his gratitude to Fudan University for the award of a Fudan Fellowship in 2018, which enabled him to stay there during the period of the paper revision.

\section{References}

Feoktistov, L.P., 1989. Neutron-induced fission wave. Sov. Phys. Dokl. 34, 1071 Teller, E., Ishikawa, M., Wood, L., 1996. Completely Automated Nuclear Reactors for Long-term Operation. In: Proceedings ICENES'96. Russia, Obninsk, pp. 151-158. Seifritz, W., 2000. Solitary burn-up waves in a multiplying medium. Kerntechnik 65 , 5.

van Dam, H., 2000. Self-stabilizing criticality waves. Ann. Nucl. Energy 27, 1505.

Sekimoto, H., Ryu, H., Yoshimura, Y., 2001. CANDLE: the new burnup strategy. Nucl. Sci. Technol. 139, 306.

Fomin, S., Mel'nik, Y.U., Pilipenko, V., Shul'ga, N., 2005. Investigation of selforganization of the non-linear nuclear burning regime in fast neutron reactors. Ann. Nucl. Energy 32, 1435.

Chen, X.-N., Kiefhaber, E., Maschek, W., 2005. Neutronic Model and its Solitary Wave Solutions for a Candle Reactor. Proceedings of ICENES'05. Belgium, Brussels.

Chen, X.-N., Maschek, W., 2005. Transverse buckling effects on solitary burn-up waves. Ann. Nucl. Energy 32, 1377.
Chen, X.-N., Kiefhaber, E., Maschek, W., 2008. Fundamental burn-up mode in a pebble-bed type reactor. Prog. Nucl. Energy 50, 219.

Chen, X.-N., Kiefhaber, E., Zhang, D., Maschek, W., 2012. Fundamental solution of nuclear solitary wave. Energy Convers. Manage. 59, 40.

Greenspan, E., 2012. A phased development of breed-and-burn reactors for enhanced nuclear energy sustainability. Sustainability 2012, 2745.

Weaver, K.D. et al., 2009. Extending the Nuclear Fuel Cycle with Traveling-Wave Reactors. Proceedings of Global 2009, Paris.

Hejzlar, P. et al., 2013. TerraPower, LLC traveling wave reactor development program overview. Nucl. Eng. Technol. 45, 731.

Schulenberg, T., Bittermann, D., Starflinger, J., 2008. Design status of the High Performance Light Water Reactor. Proceedings of 16th Pacific Basin Nuclear Conference. Aomori, Japan.

Ishiwatari, Y., Oka, Y., Koshizuka, S., 2001. Breeding ratio analysis of a fast reactor cooled by supercritical light water. J. Nucl. Sci. Technol. 38, 703.

Mori, M., 2005. Core Design Analysis of the Supercritical Water Fast Reactor Dissertation. Institute for Nuclear Energy, University of Stuttgart, Germany.

Monti, L., 2009. Multi-scale, coupled reactor physics/thermal-hydraulics system and applications to the HPLWR 3 pass core. Forschungszentrum Karlsruhe FZKA 7521.

Chen, X.-N., Zhang, D., Maschek, W., Schulenberg, T., 2010. Solitary breeding/ burning waves in a supercritical water cooled fast reactor. Energy Convers. Manage. 51, 1792

Zhang, D., Chen, X.-N., Gabrielli, F., Rineiski, A., Maschek, W., Schulenberg, T., 2011. Numerical studies of nuclear traveling waves in a supercritical water cooled fast reactor. Prog. Nucl. Energy 53, 806.

Vallet, V. et al., 2013. Introduction of thorium-based fuels in high conversion pressurized water reactors. Nucl. Technol. 182, 187.

Janin, D., Douce, S., Seidl, M., Macian, R., 2016. High conversion small modular reactor (HCSMR): core simulations with CRONOS2, APOLLO ${ }^{\circledR}$ AND TRIPOLI- ${ }^{\circledR}$. International Youth Nuclear Congress, Hangzhou, China.

Rimpault, G. et al., 2002. The ERANOS Code and Data System for Fast Reactor Neutronic Analyses. Seoul, Korea. Proc of the International Conference on the Physics of Reactors (PHYSOR 2002).

THOME, R. J., Engineering Data Book III, Chapter 17 Void Fractions in Two-Phase Flows, Wolverine Tube Inc. (2004-2010).

Zivi, S.M., 1964. Estimation of steady state steam void fraction by means of the principle of minimum entropy production. Trans. ASME J. Heat Transfer 86, 247. Groeneveld, D.C. et al., 2007. The 2006 CHF look-up table. Nucl. Eng. Des. 237, 1909. 
Karlsruher Institut für Technologie

\section{Repository KITopen}

Dies ist ein Postprint/begutachtetes Manuskript.

Empfohlene Zitierung:

Chen, X.-N.; Gabrielli, F.; Rineiski, A.; Schulenberg, T.

Boiling water cooled travelling wave reactor.

2019. Annals of nuclear energy, 134

doi:10.5445//R/1000096350

Zitierung der Originalveröffentlichung:

Chen, X.-N.; Gabrielli, F.; Rineiski, A.; Schulenberg, T.

Boiling water cooled travelling wave reactor.

2019. Annals of nuclear energy, 134, 342-349

doi:10.1016/j.anucene.2019.06.037 